\title{
EKSPLORASI PERSEPSI SISWA SEKOLAH DASAR DALAM PEMBELAJARAN HURUF HIJAIYAH BERBASIS PERMAINAN
}

\author{
Hurriatus Tsaniyah Qutby ${ }^{1^{*}}$, Saida Ulfa ${ }^{2}$, Ahmad Munjin Nasih ${ }^{3}$ \\ ${ }^{1,2}$ Teknologi Pembelajaran, Fakultas Ilmu Pendidikan, Universitas Negeri Malang \\ ${ }^{3}$ Sastra Arab, Fakultas Sastra, Universitas Negeri Malang
}

\section{Edcomtech}

\section{Jurnal Kajian Teknologi} Pendidikan

Volume 6, No 2, Oktober 2021

210-221

DOI: 10.17977/um039v6i12021p210

Submitted 14-06-2020

Accepted 13-07-2020

\section{Corresponding Author*}

Hurriatus Tsaniyah Qutby

Universitas Negeri Malang

Jl. Semarang No.5, Sumbersari, Kec. Lowokwaru, Kota Malang, Jawa Timur 65145, Indonesia Email:

hurriatus.tsania@gmail.com

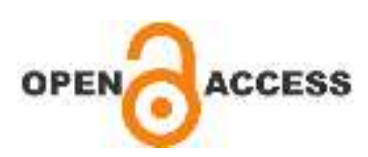

\begin{abstract}
Abstrak
Pada era digital seperti ini, anak-anak lebih tertarik bermain game pada smartphone mereka sampai muncul fenomena kecanduan game, daripada harus membaca Iqro apalagi Al-Quran. Peneliti bertujuan untuk mengetahui persepsi penggunaan mobile game base learning dalam pembelajaran huruf hijaiyah. Dalam penelitian ini menggunakan metode kuantitatif dengan pendekatan deskriptif. Teknik yang digunakan dalam pengumpulan data menggunakan teknik survei melalui penyebaran kuesioner. Kuesioner yang dikembangkan menggunakan TAM (Technology Acceptance Model). Berdasarkan hasil yang diperoleh, kegunaan dan kemudahan mobile game based learning hijaiyah dipercaya dapat meningkatkan kemampuan membaca huruf hijaiyah dan dapat diterima responden. Responden berniat menggunakan kembali mobile game based learning di masa mendatang. Penelitian ini dapat menjadi rujukan atau kontribusi tentang TAM (Technology Acceptance Model) dalam penggunaan mobile game based learning hijaiyah.
\end{abstract}

Kata kunci: mobile, game based learning, TAM, persepsi

\begin{abstract}
In this digital era, children are more interested in playing games on their smartphones until the phenomenon of game addiction arises, rather than having to read Igro let alone the Qur'an. Researchers aimed to determine the perception of the use of mobile game base learning in learning hijaiyah letters. In this study using a quantitative method with a descriptive approach. The technique used in data collection uses survey techniques through questionnaires. The questionnaire was developed using TAM (Technology Acceptance Model). Based on the results obtained, the usefulness and ease of mobile game-based learning hijaiyah is believed to improve the ability to read hijaiyah letters and be acceptable to respondents. Respondents intend to reuse mobile game based learning in the future. This research can be a reference or contribution about TAM (Technology Acceptance Model) on using mobile game based learning hijaiyah.

Keywords: mobile, game based learning, TAM, perception
\end{abstract}




\section{LATAR BELAKANG}

Anak usia sekolah dasar mempunyai keunikan. Keunikan tersebut dapat dilihat dari cara belajar pada usia sekolah dasar yang lebih suka bermain, suka bergerak, mencoba sesuatu hal baru, bekerja kelompok dan melakukan suatu hal secara langsung. Oleh karena itu, sebaiknya guru melakukan pengembangan pembelajaran yang memiliki unsur permainan, agar siswa bisa berpindah atau bergerak serta melakukan pekerjaan secara berkelompok, serta siswa diberi kesempatan supaya terlibat secara langsung dalam pembelajaran.

Keunikan yang paling menonjol dari anak usia 6-12 tahun adalah suka bermain. Suatu permainan dapat mengembangkan kecerdasan kognitif dan psikomotorik anak. Aspek kognitif memiliki keterkaitan dengan kecerdasan masing-masing individu, yaitu mampu berfikir serta memecahkan masalah. Perkembangan sel syaraf pusat di otak mempengaruhi aspek kognitif. Menurut Woolfolk dalam Latifa (2017) aspek kognitif dibedakan berdasarkan kedua bagian otak, yaitu otak kiri dan otak kanan. Bagian otak kiri memiliki keterkaitan dengan kemampuan berpikir rasional, ilmiah, memusat dan kritis. Maka kegiatan yang melibatkan fungsi otak bagian kiri adalah berhitung, membaca, belajar bahasa serta melakukan kegiatan penelitian ilmiah. Sedangkan otak bagian kanan memiliki keterkaitan dengan kemampuan berpikir imajinatif, intuitif, holistik dan menyebar. Kegiatan yang paling banyak menggunakan otak bagian kanan antara lain, bermain music, melukis, dan membuat kerajinan tangan.

Di usia anak sekolah dasar membiasakan belajar tentang agama islam seperti belajar Al-Quran merupakan suatu kewajiban yang harus ditanamkan. Biasanya para orang tua mendatangkan guru khusus untuk mendidik anaknya agar bisa membaca Al-Quran. Sebelum mempelajari Al-Quran, anak-anak wajib mempelajari huruf-huruf hijaiyah terlebih dahulu. Para guru menggunakan berbagai metode untuk mempermudah anak dalam mempelajari huruf hijaiyah mulai dari Iqro', Qiroati, Tilawati hingga metode Yanbu'a. Menurut peneliti beberapa metode tersebut memiliki kekurangan yaitu anak-anak cenderung malas mengikuti karena kurang menarik.

Pada era digital seperti ini, anak-anak lebih tertarik bermain game pada smartphone sesuai dalam Zaini \& Soenarto (2019) menunjukkan intensitas penggunaan smartphone pada anak usia 4 sampai 6 tahun yaitu sebesar sembilan puluh empat persen. Anak-anak lebih betah menghabiskan waktu berjam-jam menghadap layar smartphone mereka sampai muncul fenomena kecanduan game, daripada harus membaca Iqro apalagi Al-Quran. Hal tersebut tentunya membuat para orang tua semakin khawatir akan pendidikan agama anak di masa depan yang semakin tidak mengenal Al-Quran sebagai pedoman hidup mereka.

Dari permasalahan tersebut di era digital seperti ini perlu dikembangkan sebuah permainan yang dapat membuat anak-anak suka untuk mempelajari Al-Quran. Game adalah salah satu alternatif media yang dapat dipakai dalam suatu pembelajaran atau biasa disebut game based learning. Dalam salah satu penelitian menunjukkan bahwa siswa dapat berkonsentrasi ketika menggunakan game based learning dan sedikit mengurangi stress dari tugas belajar dan lebih mengarah ke peningkatan prestasi belajar siswa (Chang et al., 2018).

Dalam penelitian lain tentang game based learning diketahui bahwa prestasi akademik siswa meningkat selama game based learning diimplementasikan dan perilaku siswa berubah secara positif (Vu \& Feinstein, 2017). Dengan demikian game based learning dirancang untuk membantu proses belajar mengajar dimana siswa dapat belajar secara mandiri sebelum atau sesudah pembelajaran 
dan dapat memberikan stimulus dalam pembelajaran atau belajar siswa.

Game based learning dapat meningkatkan pemahaman kognitif dan tingkat pemahaman langsung lebih efektif dalam pembelajaran dan meningkatkan prestasi belajar siswa (Liu \& Chen, 2013). Anak-anak lebih mudah memahami suatu materi melalui sebuah permainan, terlebih lagi permainan yang menggunakan media smartphone, karena ketertarikan anak-anak zaman sekarang terhadap permainan pada smartphone. Para psikolog telah lama mengakui pentingnya permainan dalam pengembangan dan pembelajaran kognitif. Menurut Piaget dalam Plass, Homer, \& Kinzer (2015), misalnya, menggambarkan bermain sebagai bagian integral, dan berevolusi dengan tahapan perkembangan kognitif anak-anak. Dengan demikian menurut Piaget, bermain menjadi lebih abstrak, simbolis, dan sosial dengan melalui berbagai tahap perkembangan.

Dalam penelitian ini peneliti tidak hanya mengembangkan mobile game based learning tetapi juga meneliti bagaimana persepsi siswa setelah menggunakan mobile game based learning dengan mengadopsi model Technology Acceptance Model (TAM) untuk menganalisis penelitian. Seperti pada salah satu penelitian ditunjukkan bahwa siswa sepakat software itu mudah dipelajari dan digunakan serta berguna. Hasilnya menunjukkan bahwa persepsi kemudahan penggunaan terkait dengan sikap terhadap penggunaan perangkat lunak melalui efeknya pada persepsi pemanfaatan, sedangkan sikap terhadap penggunaan perangkat lunak sangat mempengaruhi niat untuk menggunakan perangkat lunak (To et al., 2019)

Dalam penelitian lain tidak seperti literatur TAM sebelumnya, penelitian ini menyoroti integrasi antara persepsi kepuasan dan penerimaan teknologi sesuai dengan sifat psikologis dan kepercayaan pelajar. Secara keseluruhan, model mencapai kesesuaian yang dapat diterima dan berhasil diintegrasikan niat untuk menggunakan (ITU) dan kepuasan yang dirasakan (PS). Namun, perbedaan psikologis tidak menunjukkan dampak positif pada kepuasan pelajar dan adopsi e-learning (Al-Azawei et al., 2017).

Temuan penelitian telah membuktikan teori penelitian sebelumnya bahwa persepsi kemudahan penggunaan berpengaruh positif pada persepsi manfaat, sedangkan persepsi kemudahan penggunaan dan persepsi manfaat mempunyai efek langsung terhadap sikap pada penggunaan. Selanjutnya, sikap mempengaruhi niat perilaku (Ulfa, 2017). Berdasarkan penelitian tersebut, TAM membantu menganalisis penerimaan suatu teknologi. Dengan demikian peneliti menganggap bahwa TAM membantu menganalisis persepsi siswa dalam mobile game based learning. Sesuai dengan latar belakang tersebut peneliti bertujuan untuk mengetahui persepsi penggunaan mobile game base learning pada pembelajaran huruf hijaiyah.

\section{METODE}

Peneliti menggunakan metode penelitian kuantitatif dengan pendekatan deskriptif. Metode penelitian kuantitatif adalah salah satu jenis penelitian yang memiliki spesifikasi sistematis, terstruktur dan terencana dengan jelas dari awal penelitian sampai pada pembuatan rancangan penelitian. Metode penelitian kuantitatif bisa diartikan sebagai metode penelitian yang memiliki dasar filsafat positivisme, untuk meneliti pada suatu populasi atau sampel tertentu, cara pengambilan sampel pada umumnya dilakukan secara acak, pengumpulan data memakai instrumen penelitian, analisis data bersifat statistik yang bertujuan untuk menguji suatu hipotesis yang telah ditentukan sebelumnya. Pendekatan deskriptif digunakan dalam penelitian ini dengan tujuan untuk menjelaskan objek penelitian ataupun hasil penelitian secara terperinci (Sugiyono, 2013). 
Sedangkan pengertian deskriptif merupakan suatu metode yang difungsikan untuk memberi gambaran pada objek yang diteliti melalui sampel yang telah dikumpulkan, tanpa dilakukan analisis pada sampel tersebut serta membuat kesimpulan umum (Sugiyono, 2013).

\section{Subyek Penelitian}

Peneliti melakukan kegiatan penelitian di MI Iskandar Sulaiman di daerah kota Batu yang terletak di Dusun Sekarputih Desa Pendem Kecamatan Junrejo. Subyek yang diteliti yaitu, siswa kelas 2 yang berjumlah 24 siswa yang terdiri dari 10 siswa laki-laki dan 14 siswa perempuan dengan rentan usia 7-8 tahun. Subyek tersebut ditetapkan oleh peneliti karena ingin meneliti persepsi siswa sekolah dasar tentang mobile game based learning.

\section{Jenis Data}

Penelitian ini menggunakan jenis data primer. Data primer adalah sumber data yang didapat secara langsung dari sumber data asli, sedangkan data sekunder adalah sumber data yang didapat oleh peneliti secara tidak langsung (Indriantoro,\& Supomo, 2013).

Pada penelitian ini data primer diperoleh melalui kuesioner yang disebar kepada siswa kelas 2 Madrasah Ibtidaiyah Iskandar Sulaiman.

\section{Teknik Pengumpulan Data}

Teknik pengumpulan data pada penelitian ini memakai teknik survei dengan cara menyebar kuesioner. Kuesioner yang dikembangkan menggunakan TAM (Technology Acceptance Model). Kuesioner adalah cara pengumpulan data yang dilakukan dengan memberi beberapa pertanyaan atau pernyataan kepada responden untuk dijawabnya (Sugiyono, 2015). Dalam pelaksanaan metode ini, peneliti akan berperan secara langsung untuk memperoleh data yang
Tabel 1. Indikator Kuesioner

\begin{tabular}{|c|c|c|}
\hline No & Indikator & No soal \\
\hline 1 & $\begin{array}{l}\text { Persepsi Kegunaan } \\
\text { Penggunaan } \\
\text { (Perceived Usefulness) }\end{array}$ & $1,2,3,4$ \\
\hline 2 & $\begin{array}{l}\text { Perspektif Kemudahan } \\
\text { Penggunaan } \\
\text { (Perceived Ease of Use) }\end{array}$ & $5,6,7,8$ \\
\hline 3 & $\begin{array}{l}\text { Sikap Terhadap } \\
\text { Pengaplikasian } \\
\text { (Attitude Toward } \\
\text { Using) }\end{array}$ & $9,10,11,12$ \\
\hline 4 & $\begin{array}{l}\text { Perilaku Keinginan } \\
\text { Untuk Menggunakan } \\
\text { (Behavioral Intention } \\
\text { to Use) }\end{array}$ & $13,14.15,16$ \\
\hline 5 & $\begin{array}{l}\text { Pemakaian aktual } \\
\text { (Actual Use) }\end{array}$ & $\begin{array}{l}17 \\
18,19,20\end{array}$ \\
\hline
\end{tabular}

diperlukan. Kuesioner yang disebarkan berfokus kepada siswa kelas 2 Madrasah Ibtidaiyah Iskandar Sulaiman.

\section{Variabel Penelitian}

Variabel merupakan sifat atau atribut atau nilai dari individu, obyek atau kegiatan yang memiliki jenis tertentu yang ditetapkan oleh peneliti untuk dianalisis kemudian ditarik kesimpulannya. Variabel yang dipakai pada penelitian ini menggunakan Technology Acceptance Model dengan menggunakan variabel external yaitu jenis kelamin siswa.

\section{Uji Coba Instrumen}

Untuk mengetahui valid atau tidaknya suatu kuesioner menggunakan uji validitas. Kuesioner dapat dikatakan valid jika dalam kuesioner tersebut bisa mengungkap sesuatu yang akan diukur. Uji validitas pada penelitian ini menggunakan Pearson Correlation dengan teknik menghitung korelasi antara nilai yang diperoleh dari beberapa pertanyaan. Suatu pertanyaan dapat dinyatakan valid jika signifikansinya kurang dari 0,05 (Ghozali, 2011).

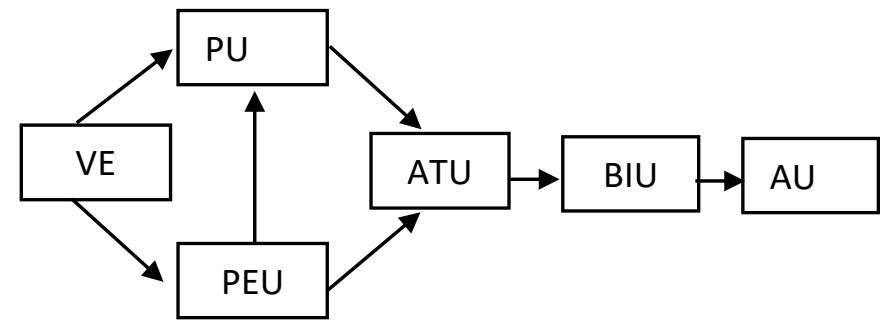

Gambar 1. Bagan Alur TAM 
Uji Reliabilitas adalah alat ukur suatu kuesioner yang merupakan indikator dari variabel. Suatu kuesioner dinyatakan reliabel jika jawaban seseorang terhadap pertanyaan selalu konsisten dari waktu ke waktu. Butir kuesioner dinyatakan reliabel jika cronbach's alpha> 0,06 dan dinyatakan tidak reliabel jika cronbach's alpha< 0,06 .

\section{Analisis Data}

Teknik analisis data dilakukan setelah data terkumpul melalui metode yang diterapkan. Analisis data adalah bagian kegiatan penelitian yang penting karena pada tahap analisis inilah kesimpulan dari suatu penelitian akan diperoleh. Sesudah pengumpulan data, maka tahap selanjutnya adalah mengelompokkan dan melakukan analisis data untuk mencapai tujuan penelitian yang telah dirumuskan.

Teknik analisis data angket siswa menggunakan analisis statistik deskriptif. Statistik deskriptif digunakan untuk menggambarkan keadaan yang sesungguhnya dari obyek yang diteliti, sedangkan statistik inferensial digunakan untuk menyimpulkan hasil analisis. Statistik deskriptif memberi gambaran objek yang diteliti dipusatkan pada mean (rata-rata), median (nilai tengah) serta modus, sedangkan persebaran data berpusat pada standar deviasi, varian, maksimum minimum serta penyajian data berbentuk pie chart.

Peneliti menggunakan analisis data kuantitatif, yaitu data yang dapat disajikan berupa angka yang didapat dari lapangan. Data kuantitatif dianalisis oleh peneliti menggunakan statistik. Peneliti menggunakan analisis anova pada program SPSS 22.0 for windows. Teknik anova dipakai guna menguji perbedaan diantara dua atau lebih kelompok dimana hanya ada satu faktor yang dipertimbangkan.
HASIL

\section{Data Uji Validitas}

Suatu kuesioner dapat dinyatakan valid apabila kuesioner dapat mengungkapkan sesuatu yang akan diukur oleh kuesioner tersebut.

Data di atas menunjukkan nilai korelasi antara item dengan skor keseluruhan. Korelasi antara PU, PEU, ATU, BIU, dan AU dengan skor keseluruhan lebih dari $r$ tabel=0,707. Jadi dapat dinyatakan bahwa kuesioner tersebut layak dan valid jika digunakan.

\section{Data Uji Reliabilitas}

Uji Reliabilitas adalah alat ukur suatu kuesioner yang merupakan indikator dari variabel. Suatu kuesioner dinyatakan reliabel jika jawaban seseorang terhadap pertanyaan selalu konsisten dari waktu ke waktu. Tabel 2 menunjukkan bahwa nilai Alpha sebesar 0,947. Nilai $r$ tabel pada signifikansi $5 \%$ dengan jumlah $\mathrm{n}=8$ adalah sebesar 0,707, mempunyai reliabilitas yang tinggi karena nilai Alpha lebih besar, maka dapat disimpulkan bahwa item dalam pertanyaan yang digunakan memiliki reliabilitas yang tinggi. jika digunakan kembali atau dilakukan pengukuran kembali akan menghasilkan skor yang tetap.

Tabel 2. Hasil Uji Validitas

\begin{tabular}{llll}
\hline No & $\mathbf{r}_{\mathbf{x y}}$ & $\mathbf{r}_{\text {tabel }}$ & Keterangan \\
\hline 1 & 0,969 & 0,707 & Valid \\
2 & 0,963 & 0,707 & Valid \\
3 & 0,972 & 0,707 & Valid \\
4 & 0,756 & 0,707 & Valid \\
5 & 0,882 & 0,707 & Valid \\
\hline
\end{tabular}

Tabel 3. Case Processing Summary

\begin{tabular}{llll}
\hline & & $\mathbf{N}$ & $\%$ \\
\hline \multirow{4}{*}{ Cases } & Valid & 8 & 100.0 \\
& Excluded $^{\mathrm{a}}$ & 0 & .0 \\
& Total & 8 & 100.0 \\
\hline
\end{tabular}

a. Listwise deletion based on all variables in the procedure.

Tahapan selanjut adalah mengukur reliabiltas seperti ditunjukkan pada Tabel 4.

Tabel 4. Reliability Statistics

\begin{tabular}{ll}
\hline Cronbach's Alpha & N of Items \\
\hline .947 & 5 \\
\hline
\end{tabular}


Tabel 5. Item-Total Statistics

\begin{tabular}{|c|c|c|c|c|}
\hline & \multirow[b]{2}{*}{$\begin{array}{l}\text { Scale } \\
\text { Mean if } \\
\text { Item } \\
\text { Deleted }\end{array}$} & \multicolumn{3}{|c|}{ Correct } \\
\hline & & $\begin{array}{c}\text { Scale } \\
\text { Varianc } \\
\text { e if } \\
\text { Item } \\
\text { Deleted }\end{array}$ & $\begin{array}{c}\text { ed } \\
\text { Item- } \\
\text { Total } \\
\text { Correla } \\
\text { tion } \\
\end{array}$ & $\begin{array}{l}\text { Cronbach } \\
\text { 's Alpha } \\
\text { if Item } \\
\text { Deleted }\end{array}$ \\
\hline $\begin{array}{l}\text { Perceived } \\
\text { Usefulness }\end{array}$ & 63.63 & 77.411 & .947 & .918 \\
\hline $\begin{array}{l}\text { Perceived } \\
\text { Ease of Use }\end{array}$ & 63.13 & 79.554 & .938 & .919 \\
\hline $\begin{array}{l}\text { Attitude } \\
\text { Toward } \\
\text { Using }\end{array}$ & 64.13 & 81.839 & .955 & .917 \\
\hline $\begin{array}{l}\text { Behavioral } \\
\text { Intention } \\
\text { to Use }\end{array}$ & 64.88 & 103.554 & .677 & .965 \\
\hline Actual Use & 65.75 & 82.786 & .805 & .946 \\
\hline
\end{tabular}

\section{Data Hasil Penelitian}

Penelitian ini menggunakan kuesioner tertutup dan disebarkan ke siswa MI Iskandar Sulaiman sebagai populasi yang diteliti setelah diberikan treatment atau belajar menggunakan mobile game based learning hijaiyah. Pengambilan data dilakukan tanggal 11 Mei 2020 sampai dengan 16 Mei 2020.

Jumlah kuesioner yang disebarkan adalah 10 dan yang mengumpulkan kuesioner berjumlah 8 kuesioner. Data kuesioner tersebut kemudian diolah pada software SPSS dan Microsoft Excel. Analisis yang disajikan adalah mean, median, modus, nilai maksimum, minimum dan disajikan melalui pie chart. Variabel penelitian dideskripsikan berikut ini.

\section{Persepsi Kegunaan Penggunaan}

Persepsi Kegunaan Penggunaan (Perceived Usefulness) adalah suatu probabilitas subjektif yang menyatakan bahwa penggunaan teknologi akan meningkatkan cara pengguna untuk menyelesaikan tugas yang telah diberikan Jahangir \& Begum (2008). Data Perceived Usefulness diperoleh dari 4 pernyataan dalam kuesioner yang menggunakan 4 pilihan jawaban. Variabel

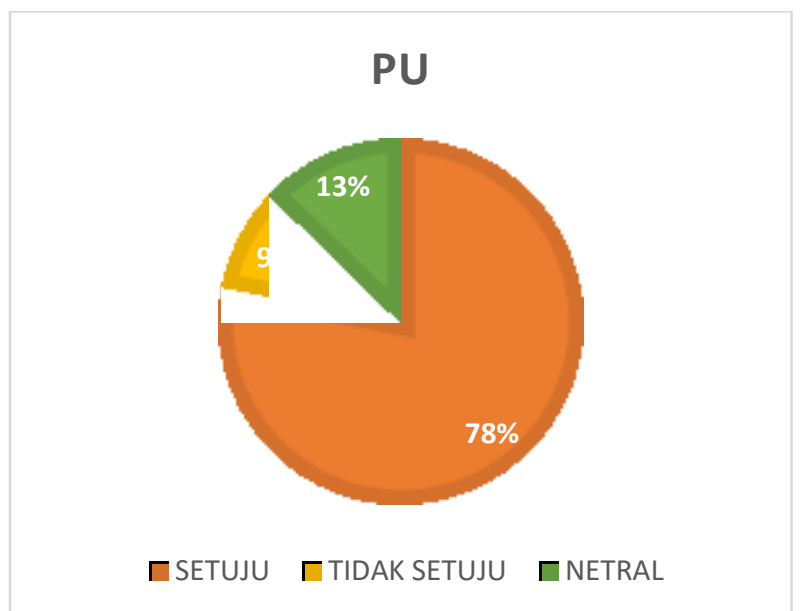

Gambar 2. Pie chart Persepsi Kegunaan Penggunaan

ini mempunyai skor terendah 2 dan yang tertinggi 20. Dari data tersebut mendapatkan data yaitu nilai mean 16,75 , nilai median 17,00 , dan nilai modus 17.

Jumlah skor pada variabel ini yang diperoleh dari responden yang diklasifikasikan menjadi 3 yaitu, setuju, tidak setuju dan netral. Dalam hal Persepsi Kegunaan dalam Penggunaan mobile game based learning hijaiyah sebanyak $78 \%$ termasuk dalam kriteria setuju, $13 \%$ termasuk dalam kriteria netral, dan 9\% termasuk dalam kriteria tidak setuju. Berdasarkan hasil yang diperoleh, kegunaan mobile game based learning hijaiyah dipercaya dapat meningkatkan kemampuan membaca huruf hijaiyah sesuai dengan persentase yang digambarkan melalui pie chart di bawah ini.

\section{Persepsi Kemudahan Penggunaan}

Menurut Rahmawati (2019) PEU mempengaruhi konstruk kegunaan, sikap, intensi dan penggunaan teknologi sesungguhnya. Tetapi yang paling signifikan adalah pengaruh ke konstruk kegunaan. Data Perceived Ease of Use diperoleh dari 4 pernyataan dalam kuesioner yang menggunakan 4 pilihan jawaban. Variabel ini mempunyai skor terendah 2 dan yang tertinggi 20. Dari data tersebut mendapatkan data yaitu nilai mean 17,25 , nilai median 17,00 , dan nilai modus 20.

Jumlah skor pada variabel ini yang diperoleh dari responden yang diklasifikasikan menjadi 3 yaitu, setuju, tidak setuju dan netral. Dalam hal Persepsi kemudahan dalam peng- 


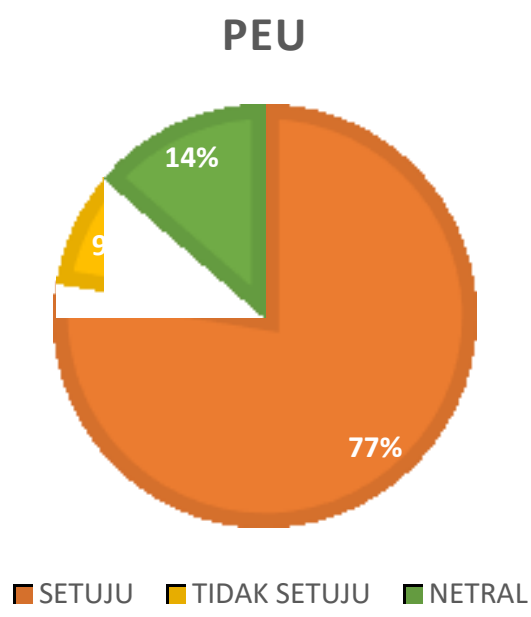

Gambar 3. Pie chart Perspektif

Kemudahan Penggunaan

-gunaan mobile game based learning hijaiyah sebanyak $77 \%$ termasuk dalam kriteria setuju, $14 \%$ termasuk dalam kriteria netral, dan 9\% termasuk dalam kriteria tidak setuju. Berdasarkan hasil yang diperoleh, kemudahan menggunakan mobile game based learning hijaiyah dipercaya dapat meningkatkan kemampuan membaca huruf hijaiyah sesuai dengan persentase yang digambarkan melalui pie chart di bawah ini.

Sikap Terhadap Pengaplikasian

Sikap terhadap penerapan suatu teknologi (attitude toward using technology), dapat dinyatakan sebagai evaluasi dari pemakai tentang keingintahuannya dalam menggunakan teknologi. Menurut Kusumawati dalam Christina (2018) penerimaan dan penggunaan teknologi tidak terlepas dari sikap terhadap perilaku penggunaan aplikasi tersebut. Sikap (attitude) merupakan suatu faktor penentu untuk niat menggunakan teknologi. Data Attitude Toward Using diperoleh dari 4 pernyataan dalam kuesioner yang menggunakan 4 pilihan jawaban. Variabel ini mempunyai skor terendah 2 dan yang tertinggi 20. Dari data tersebut mendapatkan data yaitu nilai mean 16,25 , nilai median 16,00, dan nilai modus 15 .

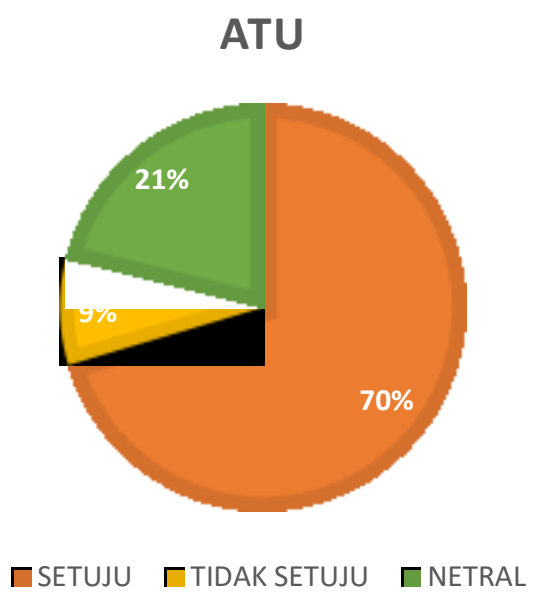

Gambar 4. Pie chart Sikap Terhadap Pengaplikasian

Jumlah skor pada variabel ini yang diperoleh dari responden yang diklasifikasikan menjadi 3 yaitu, setuju, tidak setuju dan netral. Dalam hal Persepsi sikap dalam penggunaan mobile game based learning hijaiyah sebanyak 70\% termasuk dalam kriteria setuju, 21\% termasuk dalam kriteria netral, dan 9\% termasuk dalam kriteria tidak setuju. Berdasarkan hasil yang diperoleh, mobile game based learning hijaiyah dapat diterima sesuai dengan persentase yang digambarkan melalui pie chart di bawah ini.

Perilaku Keinginan Untuk Menggunakan

$$
\text { Perilaku Keinginan Untuk }
$$

Menggunakan (Behavioral intention to use) dapat diartikan sebagai kecenderungan perilaku untuk tetap mengaplikasikan sebuah teknologi. Menurut Indrawati dalam Fauzi et al. (2018) Behavioral intention to use menggambarkan sejauh mana keinginan seorang pengguna suatu teknologi akan menggunakan lagi teknologi tersebut di masa yang akan datang. Data Behavioral Intention to Use diperoleh dari 4 pernyataan dalam kuesioner yang menggunakan 4 alternatif jawaban. Variabel ini memiliki skor terendah 2 dan skor tertinggi 20. Dari data tersebut mendapatkan data yaitu nilai mean 15,50 , nilai median 16,00, dan nilai modus 16 .

Jumlah skor pada variabel ini yang diperoleh dari responden yang diklasifikasikan menjadi 3 yaitu, setuju, tidak setuju dan netral. Dalam hal keinginan tetap menggunakan 


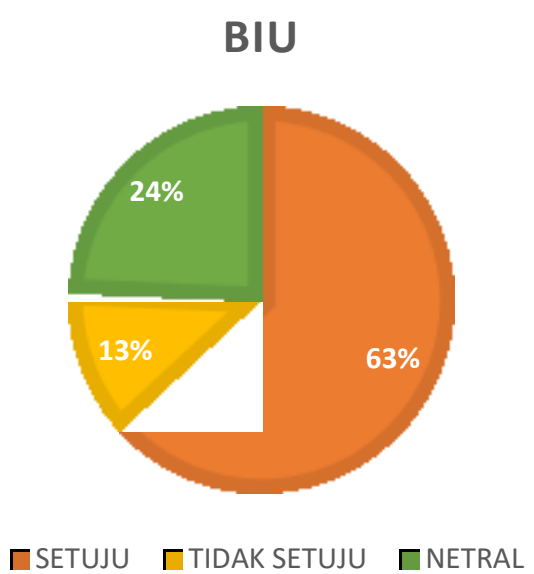

Gambar 5. Pie chart perilaku keinginan untuk menggunakan

mobile game based learning hijaiyah sebanyak $63 \%$ termasuk dalam kriteria setuju, 24\% termasuk dalam kriteria netral, dan $13 \%$ termasuk dalam kriteria tidak setuju. Berdasarkan hasil yang diperoleh, responden berkeinginan untuk tetap menggunakan mobile game based learning hijaiyah sesuai dengan persentase yang digambarkan melalui pie chart di bawah ini.

Pemakaian Aktual

Dalam salah satu penelitian menyebutkan bahwa Actual Use adalah penggunaan sesungguhnya terhadap suatu teknologi yang diukur dengan menghitung frekuensi dan durasi penggunaannya (Azizah, 2012). Data Actual Use diperoleh dari 4 pernyataan dalam kuesioner yang menggunakan 4 alternatif jawaban. Variabel ini memiliki skor terendah 2 dan skor tertinggi 20. Dari data tersebut mendapatkan data yaitu nilai mean 14,63 , nilai median 15,50 , dan nilai modus 15 .

Jumlah skor pada variabel ini yang diperoleh dari responden yang diklasifikasikan menjadi 3 yaitu, setuju, tidak setuju dan netral. Dalam hal keinginan tetap menggunakan mobile game based learning hijaiyah sebanyak $57 \%$ termasuk dalam kriteria setuju, 27\% termasuk dalam kriteria netral, dan $16 \%$ termasuk dalam kriteria tidak setuju.

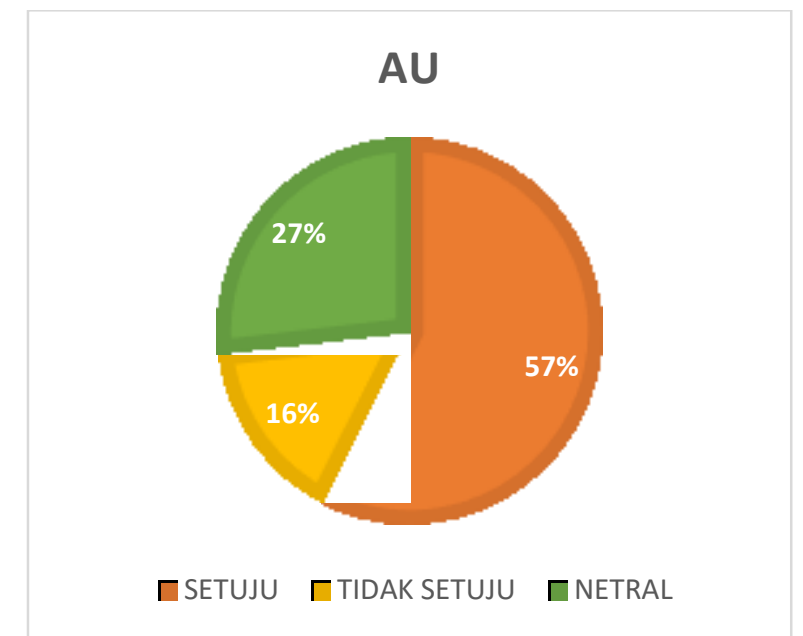

Gambar 6. Pie chart Pemakaian actual

Berdasarkan hasil yang diperoleh, lebih dari separuh responden tetap menggunakan mobile game based learning hijaiyah sebagai media untuk belajar sesuai dengan persentase yang digambarkan melalui pie chart di bawah ini.

\section{PEMBAHASAN}

Mengacu pada penelitian sebelumnya game based learning menunjukkan pencapaian yang lebih tinggi daripada pembelajaran biasa (Chang et al., 2018). Dalam penelitian lain menyebutkan game based learning sebagian besar menekankan bahwa itu adalah jenis permainan game dengan hasil pembelajaran yang ditentukan (Plass et al., 2015).

Merujuk pada penelitian yang lain bahwa game based learning dapat meningkatkan motivasi belajar dan prestasi siswa (Tsai et al., 2017). Dalam penelitian lain menunjukkan bahwa M-GBL layak dipakai untuk media pembelajaran yang praktis, menyenangkan, menarik, bisa digunakan di mana saja, serta sesuai dengan fasilitas yang dimiliki oleh siswa. M-GBL memiliki efek positif pada hasil belajar siswa ketika diaplikasikan pada kelompok siswa yang mempunyai tingkat kemandirian belajar yang tinggi (Cahyana et al., 2017).

Dalam penelitian lain menunjukkan bahwa Siswa menganggap game based learning bermanfaat untuk belajar dan meningkatkan motivasi belajar (Gamlo, 2019). Sejalan dengan penelitian yang lain 
menunjukkan bahwa siswa menunjukkan peningkatan yang signifikan pada prestasi (White \& McCoy, 2019). Sedangkan dalam penelitian yang lainnya menunjukkan bahwa game based learning meningkatkan performa positif belajar siswa (Huang et al., 2017).

Mengacu pada hasil analisis dan penelitian terdahulu menunjukkan bahwa sikap guru terhadap game based learning positif dan mereka bermaksud untuk menggunakan kembali game based learning pada proses pembelajaran yang akan datang (Akhtar et al., 2019). Dalam penelitian lain tentang game based learning diketahui bahwa prestasi akademik siswa meningkat selama game based learning diimplementasikan dan perilaku siswa berubah secara positif ( $\mathrm{Vu}$ \& Feinstein, 2017).

Dalam penelitian lain tidak seperti literatur TAM sebelumnya, penelitian ini menyoroti integrasi antara persepsi kepuasan dan penerimaan teknologi sesuai dengan sifat psikologis dan kepercayaan pelajar. Secara keseluruhan, model mencapai kesesuaian yang dapat diterima dan berhasil diintegrasikan niat untuk menggunakan dan kepuasan yang dirasakan. Namun, perbedaan psikologis tidak menunjukkan dampak positif pada kepuasan pelajar dan adopsi e-learning (Al-Azawei et al., 2017).

Dalam penelitian lain, terdapat korelasi yang signifikan antara sikap dan niat untuk memakai game based learning, antara kegunaan dan sikap, antara kemudahan penggunaan dan kegunaan yang dirasakan, hal tersebut mendukung penerapan TAM dalam GBL (Shiue \& Hsu, 2017). Sejalan dengan pernyataan tersebut TAM menyarankan persepsi kemudahan penggunaan dan persepsi manfaat sebagai 2 faktor utama yang memengaruhi cara pengguna menerima dan menggunakan teknologi (Fontil et al., 2019).
TAM menawarkan bahwa dua persepsi pengguna akhir tersebut memprediksi penerimaan teknologi: (1) kegunaan (sejauh mana seseorang percaya bahwa memakai suatu teknologi akan meningkatkan kinerja, dan (2) kemudahan penggunaan (sejauh mana penggunaan teknologi) (Holahan et al., 2015). Dalam penelitian lain menunjukkan hasil bahwa persepsi kegunaan, kemudahan dan aksesibilitas terhadap suatu teknologi pembelajaran termasuk dalam kategori baik (Qonita et al., 2019).

Merujuk pada penelitian lain Hasilnya menunjukkan bahwa sistem DGBL cocok untuk kedua jenis kelamin di semua tingkat pengalaman. Selain itu, "kemudahan penggunaan" yang dirasakan siswa kelas 4, "manfaat yang dirasakan", "sikap terhadap penggunaan", dan "niat untuk menggunakan" mengungkapkan tingkat korelasi positif dan signifikan yang tinggi (Cheng et al., 2013). Sejalan dengan penelitian tersebut tentang TAM dalam penerapan game based learning, responden pada umumnya memiliki persepsi positif karena dilihat dari sisi penerimaannya. Sikap positif responden menunjukkan bahwa responden bersedia menerima $D G B L$ dalam proses pembelajarannya.

Dalam penelitian lain menunjukkan hasil bahwa pemahaman siswa dalam penggunaan game pembelajaran lebih baik dibandingkan kelompok yang tidak menggunakan game pembelajaran (Hidayatulloh et al., 2020). Sesuai dengan hasil penelitian sebelumnya, bahwa sebagian besar responden menganggap $G B L$ tidak hanya mudah digunakan tetapi sangat membantu dalam pembelajaran (Wang et al., 2017).

Pengemasan game yang menarik direkomendasikan untuk dirancang sesuai dengan karakteristik pengguna (Surahman \& Alfindasari, 2017). Selain itu game harus memiliki kemampuan untuk menampilkan profil capaian pengguna (Ulfa et al., 2019). Data tersebut dapat berguna untuk pengambilan keputusan dalam permainan yang dikembangkan. Pengembangan media pembelajaran berbasis game mobile juga dapat 
dikembangkan untuk berbagai sumber pelajaran termasuk bahasa (Ulfa et al., 2020).

\section{SIMPULAN}

Berdasarkan hasil yang diperoleh, kegunaan dan kemudahan mobile game based learning hijaiyah dipercaya dapat meningkatkan kemampuan membaca huruf hijaiyah dan dapat diterima responden. Responden berniat menggunakan kembali mobile game based learning dimasa yang akan datang. Penelitian ini sudah dilakukan sesuai dengan prosedur penelitian yang dipilih, tetapi dalam penelitian ini masih ada beberapa keterbatasan pada jumlah responden karena saat penelitian dilakukan bersamaan dengan terjadinya pandemic Covid-19. Peneliti menyarankan kepada peneliti lain supaya dapat melakukan kegiatan penelitian lain yang lebih baik dengan jumlah responden yang lebih besar. Untuk guru TPQ/ guru agama islam di sekolah disarankan untuk menggunakan mobile game based learning hijaiyah sebagai media untuk belajar.

\section{REFERENSI}

Akhtar, H., Hasanati, N., \& Istiqomah. (2019). Game-Based Learning: Teachers' Attitude and Intention To Use Quizizz in the Learning Process. The 2nd International Conference on Educational Assessment and Policy, Iceap, 49-54.

Al-Azawei, A., Parslow, P., \& Lundqvist, K. (2017). Investigating the effect of learning styles in a blended e-learning system: An extension of the technology acceptance model (TAM). Australasian Journal of Educational Technology, 33(2), 1-23. https://doi.org/10.14742/ajet.2741

Azizah, siti tutik muntianah; endang siti astuti;devi farah. (2012). Pengaruh minat perilaku terhadap. Profit, 6(1),
88-113.

Cahyana, U., Paristiowati, M., Savitri, D. A., \& Hasyrin, S. N. (2017). Developing and application of mobile game based learning (M-GBL) for high school students performance in chemistry. Eurasia Journal of Mathematics, Science and Technology Education, 13(10), 7037-7047. https://doi.org/10.12973/ejmste/78728

Chang, C. C., Warden, C. A., Liang, C., \& Lin, G. Y. (2018). Effects of digital game-based learning on achievement, flow and overall cognitive load. Australasian Journal of Educational Technology, 34(4), 155-167. https://doi.org/10.14742/ajet.2961

Cheng, Y. M., Lou, S. J., Kuo, S. H., \& Shih, R. C. (2013). Investigating elementary school students' technology acceptance by applying digital game-based learning to environmental education. Australasian Journal of Educational Technology, 29(1), 96-110. https://doi.org/10.14742/ajet.65

Christina, H. (2018). Analisis Penerimaan dan Penggunaan Teknologi Ojek Online. 6(1), 34-44.

Fauzi, A., Widodo, T., \& Djatmiko, T. (2018). Pengaruh Behavioral Intention Terhadap Use Behavior Pada Penggunaan Aplikasi Transportasi Online (Studi Kasus Pada Pengguna Go-Jek Dan Grab Di Kalangan Mahasiswa Telkom University ). EProceeding of Management, 5, no.2(October), 1195-1200.

Fontil, V., Radcliffe, K., Lyson, H. C., Ratanawongsa, N., Lyles, C., Tuot, D., Yuen, K., \& Sarkar, U. (2019). Testing and improving the acceptability of a webbased platform for collective intelligence to improve diagnostic accuracy in primary care clinics. JAMIA Open, 2(1), 40-48. https://doi.org/10.1093/jamiaopen/ooy0 58

Gamlo, N. (2019). The Impact of Mobile GameBased Language Learning Apps on EFL Learners' Motivation. English Language Teaching, 12(4), 49-56. https://doi.org/10.5539/elt.v12n4p49

Ghozali, I. (2011). Aplikasi analisis multivariate 
dengan program IBM SPSS 19. Badan Penerbit Universitas Diponegoro, 68. Hidayatulloh, S., Praherdhiono, H., \& Wedi, A. (2020). Pengaruh Game Pembelajaran Terhadap Peningkatan Hasil Belajar Pemahaman IImu Pengetahuan Alam. JKTP: Jurnal Kajian Teknologi Pendidikan, 3(2), 199-206.

https://doi.org/10.17977/um038v3i 22020p199

Holahan, P. J., Lesselroth, B. J., Adams, K., Wang, K., \& Church, V. (2015). Beyond technology acceptance to effective technology use: A parsimonious and actionable model. Journal of the American Medical Informatics Association, 22(3), 718729.

https://doi.org/10.1093/jamia/ocu0 43

Huang, Y. L., Chang, D. F., \& Wu, B. (2017). Mobile game-based learning with a mobile app: Motivational effects and learning performance. Journal of Advanced Computational Intelligence and Intelligent Informatics, 21(6), 963-970.

https://doi.org/10.20965/jaciii.2017. p0963

Jahangir, N., \& Begum, N. (2008). The role of perceived usefulness, perceived ease of use, security and privacy, and customer attitude to engender customer adaptation in the context of electronic banking. African Journal of Business Management, 2(2), 3240.

Latifa, U. (2017). Aspek Perkembangan pada Anak Sekolah Dasar: Masalah dan Perkembangannya. Journal of Multidisciplinary Studies, 1(2), 185196.

Liu, E. Z. F., \& Chen, P.-K. (2013). The Effect of Game-Based Learning on Students' Learning Performance in Science Learning - A Case of "Conveyance Go." Procedia - Social and Behavioral
Sciences, 103, 1044-1051. https://doi.org/10.1016/j.sbspro.2013.10 .430

Plass, J. L., Homer, B. D., \& Kinzer, C. K. (2015). Foundations of Game-Based Learning. Educational Psychologist, 50(4), 258-283. https://doi.org/10.1080/00461520.2015. 1122533

Qonita, A., Sulton, S., \& Soepriyanto, Y. (2019). Persepsi kegunaan, persepsi kemudahan dan aksesibilitas mahasiswa fakultas ilmu pendidikan angkatan 2018 terhadap penerapan sipejar menggunakan model tam (technology acceptance model). In Jurnal Kajian Teknologi Pendidikan (pp. 140-148). State University of Malang (UM).

https://doi.org/10.17977/um038v2i2201 9p140

Rahmawati N; Narsa, I Made, R. (2019). http://journal.uny.ac.id/index.php/jitp. 6(2), 127-136.

Shiue, Y. M., \& Hsu, Y. C. (2017). Understanding factors that affecting continuance usage intention of game-based learning in the context of collaborative learning. Eurasia Journal of Mathematics, Science and Technology Education, 13(10), 64456455.

https://doi.org/10.12973/ejmste/77949

Sugiyono. (2015). Metode Penelitian Kuantitatif, Kualitatif dan R\&D. Penerbit Alfabeta.

file://C:/Users/HP/AppData/Local/Mend eley Ltd./Mendeley Desktop/Downloaded/Sugiyono - 2015 Metode Penelitian Kuantitatif, Kualitatif dan R\&D.pdf

Surahman, E., \& Alfindasari, D. (2017). Developing adaptive mobile learning with the principle of coherence Mayer on biology subjects of high school to support the open and distance education. 3rd International Conference on Education and Training (ICET 2017). Atlantis Press, 184-190.

To, W. M., Lai, L. S. L., \& Leung, V. W. S. (2019). Technology acceptance model for the 
intention to use advanced business application software among Chinese business school students. Australasian Journal of Educational Technology, 35(4), 160-173. https://doi.org/10.14742/ajet.4942

Tsai, C. H., Cheng, C. H., Yeh, D. Y., \& Lin, S. Y. (2017). Can learning motivation predict learning achievement? A case study of a mobile game-based English learning approach. Education and Information Technologies, 22(5), 2159-2173.

ttps://doi.org/10.1007/s10639-0169542-5

Ulfa, S. (2017). Exploring Studentâ $€^{T M} s$ Perceptions of Computer based Testing for University Entrance Examination By Using Technology Acceptance Model : Case Study State University of Exploring Student' $s$ Perceptions of Computer based Testing for University Entrance Exa. 8(2), 0-8.

Ulfa, S., Fattawi, I., Surahman, E., \& Yusuke, H. (2019). Investigating Learners' Perception of Learning Analytics Dashboard to Improve Learning Interaction in Online Learning System. 2019 5th International Conference on Education and Technology (ICET), 4954.

https://doi.org/10.1109/ICET48172.
2019.8987229

Ulfa, S., Surahman, E., \& Octaviani, H. I. (2020). Mobile Seamless Language Learning Framework to Improving Students' Speaking Skills for Junior High Students during Pandemic Convid-19: A Case Study in Indonesian Context. 1st International Conference on Information Technology and Education (ICITE 2020), 497-500.

Vu, P., \& Feinstein, S. (2017). An Exploratory Multiple Case Study about Using GameBased Learning in STEM Classrooms. International Journal of Research in Education and Science, 3(2), 582-588. https://doi.org/10.21890/ijres.328087

Wang, C. S., Huang, Y. M., \& Hsu, K. S. (2017). Developing a mobile game to support students in learning color mixing in design education. Advances in Mechanical Engineering, 9(2), 1-6. https://doi.org/10.1177/1687814016685 226

White, K., \& McCoy, L. P. (2019). Effects of Game-Based Learning on Attitude and Achievement in Elementary Mathematics. Networks: An Online Journal for Teacher Research, 21(1), 1-17. https://doi.org/10.4148/2470-6353.1259

Zaini, M., \& Soenarto, S. (2019). Persepsi Orangtua Terhadap Hadirnya Era Teknologi Digital di Kalangan Anak Usia Dini. Jurnal Obsesi: Jurnal Pendidikan Anak Usia Dini, 3(1), 254-264. https://doi.org/10.31004/obsesi.v3i1.127 